Journal of Zhejiang University-SCIENCE B (Biomedicine \& Biotechnology) ISSN 1673-1581 (Print); ISSN 1862-1783 (Online)

www.zju.edu.cn/jzus; www.springerlink.com

E-mail: jzus@zju.edu.cn

\title{
Review:
}

\section{Hypoxia-inducible factor 1 and breast cancer metastasis}

\author{
Zhao-ji LIU ${ }^{1}$, Gregg L. SEMENZA ${ }^{2}$, Hua-feng ZHANG ${ }^{\dagger 1}$ \\ $\left({ }^{1}\right.$ CAS Key Laboratory of Innate Immunity and Chronic Disease, Innovation Center for Cell Biology, \\ School of Life Sciences, University of Science and Technology of China, Hefei 230027, China) \\ ( ${ }^{2} J o h n s$ Hopkins University School of Medicine, Baltimore, MD 21205, USA) \\ †E-mail: hzhang22@ustc.edu.cn
}

Received Aug. 11, 2014; Revision accepted Nov. 6, 2014; Crosschecked Dec. 18, 2014

\begin{abstract}
Accumulating evidence has shown that the hypoxic microenvironment, which is critical during cancer development, plays a key role in regulating breast cancer progression and metastasis. The effects of hypoxia-inducible factor 1 (HIF-1), a master regulator of the hypoxic response, have been extensively studied during these processes. In this review, we focus on the roles of HIF-1 in regulating breast cancer cell metastasis, specifically its effects on multiple key steps of metastasis, such as epithelial-mesenchymal transition (EMT), invasion, extravasation, and metastatic niche formation. We also discuss the roles of HIF-1-regulated non-coding RNAs in breast cancer metastasis, and therapeutic opportunities for breast cancer through targeting the HIF-1 pathway.
\end{abstract}

Key words: Breast cancer, Hypoxia-inducible factor 1 (HIF-1), Metastasis doi: 10.1631 /jzus.B1400221

Document code: A

CLC number: R737.9; Q2

\section{Hypoxic microenvironment and breast cancer}

Hypoxia has been extensively studied for decades within the tumor microenvironment, which influences malignant cells in various ways ( $\mathrm{Hu}$ and Polyak, 2008). While the $\mathrm{O}_{2}$ supply matches the need of cell growth in normal tissues, the diffusion of $\mathrm{O}_{2}$ from a blood capillary in a tumor mass that reaches a size of $1-2 \mathrm{~mm}^{3}$ is limiting because of structural and functional abnormalities of the newly formed tumor vessels, thus leading to the development of hypoxic areas in the tumor mass (Vaupel et al., 2004).

\footnotetext{
"Corresponding author

* Project supported partially by the National Basic Research Program (973) of China (Nos. 2014CB910604 and 2012CB910104), the National Natural Science Foundation of China (Nos. 31171358 and 31371429), the Research Fund for the Doctoral Program of Higher Education of China (No. 20133402110020), the Fundamental Research Funds for the Central Universities in China, and the ' 1000 Youth Talent Program' by the Chinese Government for Hua-feng ZHANG (iD) ORCID: Hua-feng ZHANG, http://orcid.org/0000-0001-9923-7531 (C) Zhejiang University and Springer-Verlag Berlin Heidelberg 2015
}

Breast cancer is the most frequently diagnosed cancer and a major cause of death in women worldwide (Jemal et al., 2011; Lech and Przemyslaw, 2011). About $25 \%-40 \%$ of invasive breast cancers exhibit hypoxic regions (Lundgren et al., 2007). Studies using polarographic electrodes have shown that the median partial pressure of oxygen $\left(\mathrm{pO}_{2}\right)$ in normal human breast tissue is $65 \mathrm{mmHg}(1 \mathrm{mmHg}=$ 133.3 Pa). In contrast, human breast cancers have a median $\mathrm{pO}_{2}$ of $10 \mathrm{mmHg}$. In addition, more than half of all breast cancers studied had a $\mathrm{pO}_{2}$ of less than $2.5 \mathrm{mmHg}$ (Vaupel et al., 1991; 2007; Hohenberger et al., 1998). Studies have shown that intra-tumoral hypoxia has negative implications for survival of breast cancer patients, independent of prognostic parameters, such as the clinical tumor stage, histological grade, and lymph node status. Hypoxic tumors are associated with a more aggressive phenotype, increased risk of metastasis, increased resistance to radiotherapy and chemotherapy, and induced cancer immune suppression (Brizel et al., 1996; Mees et al., 2009). 


\section{Basic biology of hypoxia-inducible factor 1 (HIF-1)}

In most human solid tumors, adaptation to decreased $\mathrm{O}_{2}$ availability is achieved primarily through the activity of two hypoxia-inducible factors (HIF-1 and HIF-2), which regulate the expression of over 1000 target genes (Semenza, 2012). Overexpression of HIF-1 has been confirmed in many solid tumors, including ovarian, bladder, uterus, breast, colon, brain, pancreatic, renal, and prostate (Zhong et al., 1999; Talks et al., 2000). HIF-1 is a hetero-dimeric transcription factor consisting of a constitutively expressed HIF-1 $\beta$ subunit (also known as the aryl hydrocarbon receptor nuclear translocator [ARNT]) and a tightly regulated HIF-1 $\alpha$ subunit (Wang et al., 1995). Both HIF- $1 \alpha$ and HIF- $1 \beta$ are members of the bHLHPAS superfamily of proteins containing basic-helixloop-helix (bHLH) and PER-ARNT-SIM (PAS) domains involved in DNA binding and dimerization, respectively (Wang et al., 1995). HIF-1 $\alpha$ also contains an oxygen-dependent degradation (ODD) domain and two transactivation domains (N-TAD and C-TAD).

$\mathrm{O}_{2}$ regulates HIF-1 $\alpha$ stability and activity through hydroxylation of proline and asparagine residues. Under normoxic conditions, two proline residues (P402 and P564) in the human HIF-1 $\alpha$ ODD domain are hydroxylated by prolyl hydroxylase domain proteins (PHDs). Hydroxylation is required for binding of the HIF-1 $\alpha$ protein to the von HippelLindau protein (VHL). VHL is the recognition subunit of an E3 ubiquitin ligase that adds a poly-ubiquitin chain to HIF-1 $\alpha$, which targets the protein for degradation in the proteasome. Morever, $\mathrm{O}_{2}$-dependent hydroxylation of asparagine residue 803 (N803) in HIF-1 $\alpha$ by factor inhibiting HIF-1 (FIH-1) suppresses the interaction of HIF- $1 \alpha$ with the coactivators p300 and CBP (CREB binding protein), and therefore inhibits the HIF-1 $\alpha$ transactivation function under normoxic conditions (Mahon et al., 2001; Lando et al., 2002). Under hypoxic conditions, both the prolyl and asparaginyl hydroxylation reactions are inhibited, leading to the stabilization of HIF-1 $\alpha$ protein and increased interaction with its co-activators. Thus, in hypoxic cells, HIF-1 $\alpha$ protein accumulates, heterodimerizes with HIF-1, binds to the consensus DNA sequence 5'-RCGTG-3' within hypoxia response elements (HREs) located in target genes, and activates their transcription (Fig. 1).

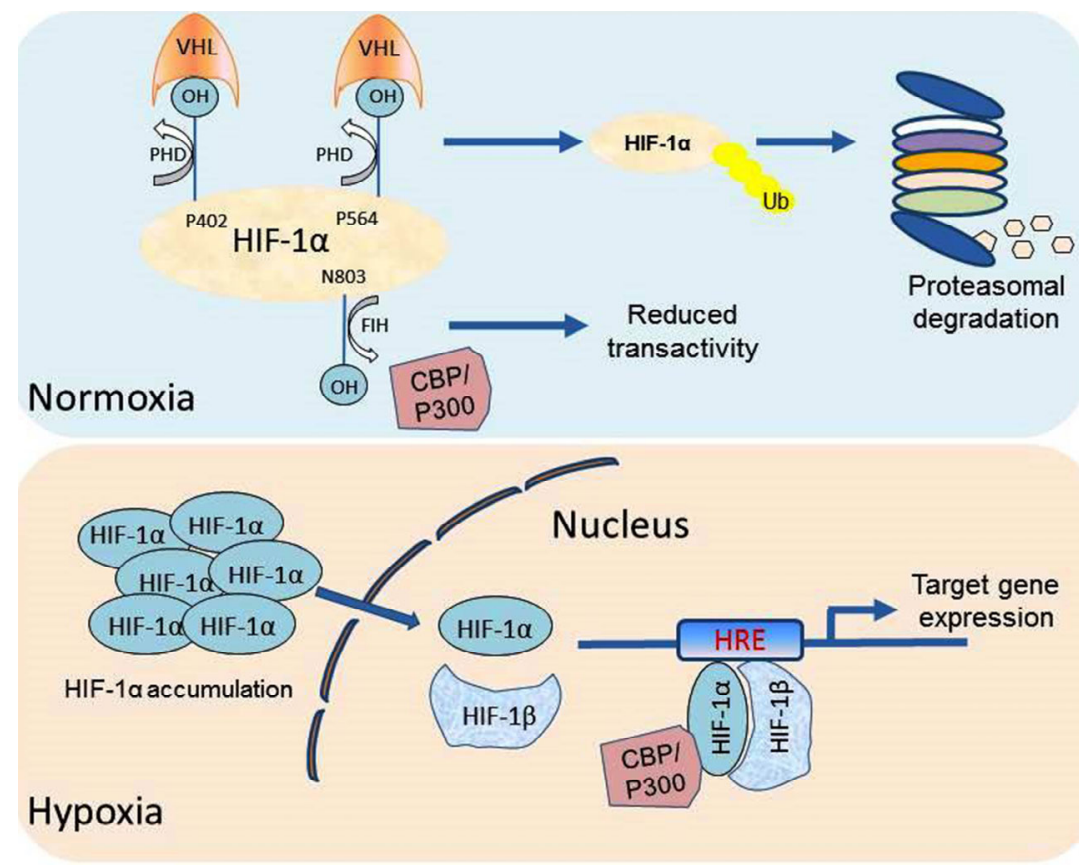

VHL: von Hippel-Lindau protein; PHD: prolyl hydroxylase domain protein; CBP: CREB binding protein; HRE: hypoxia response element; Ub: ubiquitin; FIH: factor inhibiting HIF

Fig. 1 Hypoxia-inducible factor 1 (HIF-1) regulated by oxygen tension 
It is not only that the HIF-1 pathway is regulated by oxygen tension, but also that hypoxia-independent growth factor stimulation, loss of tumor suppressor function, and oncogenic activation have been reported to regulate HIF-1 $\alpha$ activity (Semenza, 2003). Growth factor signals affecting the HIF-1 $\alpha$ pathway include human insulin-like growth factor, human epidermal growth factor (EGF), and prostaglandin E2 (Feldser et al., 1999; Laughner et al., 2001; Fukuda R. et al., 2002; Liu et al., 2002; Fukuda N. et al., 2003; Grimshaw, 2007). Function loss of tumor suppressor proteins, such as VHL, phosphatase, and phosphatase and tension homolog deleted on chromosome 10 (PTEN) and p53 in cancer cells, impairs the degradation of HIF-1 $\alpha$ protein, or increases the synthesis of HIF-1 (Krieg et al., 2000; Zhong et al., 2000; Zundel et al., 2000; Ravi et al., 2001), thus leading to HIF-1 $\alpha$ protein accumulation. Activation of the oncogenic PI3K/Akt signaling pathway stimulates HIF-1 $\alpha$ expression through mTORdependent translation (Zhong et al., 2000; Laughner et $a l ., 2001)$. In addition, cellular reactive oxygen species and nitric oxide have also been shown to stabilize HIF-1 $\alpha$, causing protein accumulation (Kasuno et al., 2004; Quintero et al., 2006; Gao et al., 2007).

\section{HIF-1 and breast cancer metastasis}

Over $90 \%$ of all breast cancer deaths are the result of metastasis, primarily to the bone, lung, liver, brain and lymph nodes. Tumor metastasis is the dissemination of cancer cells from the initial site of primary tumor growth to distant organs where they survive, proliferate, and form secondary tumors. Metastasis is a complex process containing a series of discrete steps: (1) epithelial-mesenchymal transition (EMT), during which cancer cells lose cell-to-cell contact and gain motility; (2) local tissue invasion, which is facilitated by the degradation of extracellular matrix (ECM); (3) intravasation, during which cancer cells penetrate the wall of a blood vessel and enter the circulation; (4) homing, during which cancer cells must survive within the circulation; (5) extravasation, during which cancer cells pass through the vascular wall and exit the blood stream at distant organs; and, (6) metastatic niche formation at the metastatic site to create a milieu that is favorable for cancer cell growth.

A high level of HIF- $1 \alpha$ at diagnosis is predictive of early relapse and metastasis, and correlates with poor clinical outcomes in human breast cancer (Bos et al., 2003; Gruber et al., 2004; Generali et al., 2006). It has been reported that expression of HIF-1 target genes is increased in the triple-negative breast cancer subgroup (Zhong et al., 1999; Cancer Genome Atlas Network, 2012). HIF-1 plays key roles in many crucial aspects of breast cancer biology, including angiogenesis, stem cell maintenance, metabolic reprogramming, EMT, invasion, metastasis, and resistance to radiation therapy and chemotherapy (Semenza, 2012). Inhibition of HIF-1 activity in mice after orthotopic transplantation of triple-negative breast cancer cells has a dramatic effect on primary tumor growth as well as metastasis to lymph nodes and lungs (Zhang et al., 2012). Understanding the molecular and cellular mechanisms underlying metastasis is required for accurate prognoses and for developing new therapeutic strategies. Recent studies have shown that the HIF-1 pathway regulates breast cancer metastasis through multiple mechanisms. Next, we will focus on the regulatory roles of HIF-1 in a series of discrete steps of breast cancer metastatic progression.

\subsection{HIF-1 mediates EMT}

During metastasis, epithelial cells detach from the primary tumor, adhere to and invade the surrounding stroma, intravasate into the bloodstream, and disseminate to distant tissues where they extravasate out of blood vessels and form secondary tumors. The process of epithelial cells detaching from primary tumors closely resembles that of cells undergoing EMT, and EMT has been regarded as the possible first step in the complex process of metastasis (Chaffer and Weinberg, 2011; Valastyan and Weinberg, 2011). Epithelial cells that undergo EMT lose their epithelial phenotype and acquire mesenchymal cell-associated characteristics (Thiery, 2002; Kalluri and Weinberg, 2009; Creighton et al., 2010; Singh and Settleman, 2010; May et al., 2011). Thus, EMT is characterized by cellular and molecular changes that include loss of cell-to-cell adhesion, which involves E-cadherin in adherent junctions and claudins in tight junctions, upregulation of the mesenchymal protein vimentin, reorganization of the cytoskeleton to acquire a more spindle-like morphology, and increased motility that involves dynamic actin microfilament networks. 
HIF-1 provokes EMT through up-regulating EMT-associated transcription factors or repressors, activating the EMT-associated signaling pathways, modulating EMT-associated inflammatory cytokines, as well as regulating other pathways like epigenetic regulators (Bao et al., 2012). For instance, HIF-1 induces EMT through the transcriptional control of E-cadherin, SNAIL (zinc finger protein snail), ZEB1 (zinc finger E-box-binding homeobox 1), TWIST, and TCF3 (transcription factor 3, also known as E47) (Krishnamachary et al., 2006; Moreno-Bueno et al., 2008). In breast cancer cells, EMT was activated by ZEB1-MYB-E-cadherin signaling under hypoxic stress, which induced higher expression of ZEB1 and lower expression of MYB (Hugo et al., 2013). Recently, it has been discovered that hypoxia-induced biomolecules, including Jagged2, cyclooxygenase-2 (COX-2), and urokinase receptor (uPAR) (Jo et al., 2009; Xing et al., 2011; Bocca et al., 2014), also contribute to EMT changes and invasive ability of breast cancer cells. The HIF-1 pathway may also regulate EMT via regulating long non-coding RNAs (lncRNAs; such as H19 lncRNA) and calcium signaling in breast cancer cells to promote cancer cell invasion in hypoxic microenvironments (Lock et al., 2013; Davis et al., 2014; Matouk et al., 2014).

\subsection{HIF-1 mediates invasion and intravasation}

To invade the surrounding tissues, cancer cells need to degrade the surrounding basement membrane (BM) and extracellular matrix barriers. Matrix metallo-proteinases (MMPs) are members of zincdependent endo-peptidases that degrade many of the components of the ECM, including the BM. Among MMPs, MMP-2 and MMP-9 degrade type IV collagen, which is a major component of the BM. MMP-2 and MMP-9 have been positively correlated with a higher incidence of metastases and with a poor prognosis in breast cancer (Duffy et al., 2000; Pritchard et al., 2001; Incorvaia et al., 2007). Cells at the invasive front of solid tumors are frequently found to have a high expression level of HIF-1 $\alpha$ (Horrée et al., 2007). Many reports suggest that hypoxia and HIF-1 upregulate the expression levels and/or activities of MMP-2 and MMP-9 (Krishnamachary et al., 2006; Munoz-Najar et al., 2006).

Type I collagen is very important for cell migration during invasion. When tumor size increases, collagen fibers straighten and align, which facilitates cancer cell invasion (Maglione et al., 2006; Provenzano et al., 2006; Conklin et al., 2011). Recent studies showed that HIF-1 $\alpha$ plays a critical role in collagen biogenesis in breast cancers by upregulating the expression levels of pro-collagen prolyl (P4HA1 and P4HA2) and lysyl (PLOD1 and PLOD2) hydroxylases in both cancer and stromal cells (Gilkes et al., 2013a; 2013b; 2013c). P4HA1 and P4HA2 are required for collagen deposition, while PLOD2 is important for collagen fiber crosslinking (Gilkes et al., 2013a). Expression of P4HA1, P4HA2, and PLOD2 is required for breast cancer metastasis.

\subsection{HIF-1 and extravasation}

Breast cancer cells may spread via either the lymphatic or vascular circulation (Weigelt et al., 2005). However, less than $0.1 \%$ of cancer cells that enter the vascular circulation establish a metastatic lesion (Fidler, 1970). This indicates that extravasation of cancer cells from the circulation into a tissue microenvironment where cancer cells can survive and proliferate is a limiting step in the metastatic process. To extravasate, a cancer cell must first adhere to endothelial cells (ECs) in the lung vasculature, a process known as margination, and then disrupt the tight interactions between ECs to penetrate out of the blood vessel.

Zhang et al. (2012) showed that HIF-1 promoted the extravasation of breast cancer cells in the lung. In addition, the invasion of naive breast cancer cells through EC monolayers increased when the cells were exposed to conditioned medium generated by hypoxic breast cancer cells. Biophysical measurement of EC-EC interactions using transendothelial electrical resistance showed decreased EC-EC interactions in the presence of conditioned medium generated by hypoxic breast cancer cells. These effects were not observed when conditioned medium from hypoxic breast cancer cells expressing shRNAstargeting HIF-1 was used (Zhang et al., 2012). Further experiments identified angiopoietin-like 4 (ANGPTL4) as a factor secreted from cancer cells that was induced by hypoxia in an HIF-1-dependent manner. ANGPTL4 expression in cancer cells disrupts vascular EC-EC junctions, increases the permeability of lung capillaries, and facilitates the extravasation of cancer cells (Padua et al., 2008). In vivo 
studies also showed that ANGPTL4 induced vascular leakiness and facilitated lung metastasis in mice (Huang et al., 2011). ANGPTL4 expression in primary breast cancers is associated with lung metastasis (Padua et al., 2008).

Hypoxic breast cancer cells also showed increased adherence to EC monolayers in an HIF-1dependent manner. Microarray analysis of metastasisrelated genes identified a cell surface receptor, $\mathrm{L} 1$ cell adhesion molecule (L1CAM), which is a direct transcriptional target of HIF-1 induced by hypoxia in triple negative breast cancer cells (Zhang et al., 2012) L1CAM is a protein involved in mediating cell-cell adherence by homophilic and heterophilic interactions with integrins, neuropilin 1, or CD24 (Semenza, 2012). Overexpression of L1CAM in cancer cells promoted the adhesion of cancer cells to EC monolayers in vitro, and increased the number of extravasated cancer cells in lung tissue after tail vein injection (Zhang et al., 2012). HIF-regulated SDF-1/ CXCR4 (stromal cell-derived factor-1/CXC chemokine receptor 4) signaling in ECs under hypoxic conditions may also promote the adhesion of breast cancer cells to ECs (Jin et al., 2012).

\subsection{HIF-1 and metastatic niche formation}

HIF-1 also regulates premetastatic niche formation at distant organs prior to cancer cell arrival (Erler et al., 2006; 2009; Wong et al., 2011; 2012). During metastasis, bone marrow-derived cells (BMDCs) are recruited to metastatic sites, where they form cell clusters that precede tumor cell arrival and are subsequently colonized by metastatic cancer cells (Kaplan et al., 2005; Xing et al., 2011). Hypoxic breast cancer cells produce multiple members of the lysyl oxidase (LOX) family, including LOX, LOXL2, and LOXL4, in an HIF-1-dependent manner (Erler et al., 2009; Wong et al., 2011; 2012). LOX family members are enzymes secreted from primary breast cancer cells that catalyze collagen crosslinking at hydroxylated lysine residues. LOX was initially found to remodel ECM in the primary tumor. Recent studies revealed that LOX can remodel ECM at sites distant from the primary tumor. Primary breast cancer cells secrete LOX family members into the circulation, leading to collagen crosslinking in metastatic tissues, which facilitates the recruitment of BMDCs and, subsequently, breast cancer premetastatic niche formation (Erler et al., 2006; 2009; Wong et al., 2011; 2012). In addition, $\mathrm{CD} 11 \mathrm{~b}^{+} / \mathrm{Ly} 6 \mathrm{C}^{\mathrm{med}} / \mathrm{Ly}_{6} \mathrm{G}^{+}$myeloid cells and $\mathrm{CD}^{-} / \mathrm{NK} 1.1^{+}$natural killer cells are two BMDC populations that promote metastasis. Indeed, it has been found that recruitment of $\mathrm{CD}_{11 \mathrm{~b}}$ / Ly6 $\mathrm{C}^{\mathrm{med}} / \mathrm{mLy} 6 \mathrm{G}^{+}$cells was enhanced by hypoxic breast cancer cells (Sceneay et al., 2012).

Interestingly, LOX family members, LOX, LOXL2, and LOXL4 have variable expression in human breast cancers and breast cancer cell lines (Wong et al., 2011). A clinical study revealed that LOX expression was associated with intra-tumoral oxygen tension and metastases of breast cancer in patients (Erler et al., 2006). Since LOX family members are extracellular secreted proteins that play critical roles in metastasis, a monoclonal antibody or small molecule inhibitor directed against LOX might be useful for breast cancer therapy.

\section{HIF-1-regulated non-coding RNA in breast cancer metastasis}

HIF-1 plays important roles in breast cancer metastasis by mediating hypoxia-induced expression of mRNA-encoding genes. HIF-1 also regulates the expression of non-coding RNAs, which are critical regulators of migration, invasion, and metastasis. Various types of non-coding RNAs have been implicated in cancer progression, such as microRNAs (miRNAs), lncRNAs, endogenous small interfering RNAs (endsiRNAs), PIWI-interacting RNAs (piRNAs), circular RNAs (circRNAs), and long intergenic non-coding RNAs (lincRNAs) (Ling et al., 2013). Non-coding RNAs play pivotal roles in migration and invasion of breast carcinoma cells, and provide new insights into the molecular mechanisms that determine metastatic propensity. In this section, we summarize the published research reporting HIF-1-regulated non-coding RNAs in the pathogenesis of breast cancer metastasis, with an emphasis on miRNAs and lncRNAs.

HIF-1 regulates the expression of many miRNAs in breast cancer cells. In MCF-7 breast cancer cells, 41 miRNAs were significantly up-regulated and 28 miRNAs were down-regulated by the hypoxic treatment (Camps et al., 2014). Expression of miR-210, for instance, which is induced by HIF-1 in most cancer cells, promotes tumor proliferation and 
invasion, and is associated with a poor clinical outcome in breast cancer (Volinia et al., 2012). miR-10b is activated by HIF-1/TWIST1 (twist-related protein 1) signaling, and overexpression of miR-10b initiates robust invasion and metastasis in otherwise nonmetastatic breast cancers (Ma et al., 2007; 2010; Haque et al., 2011). miR-20a and miR-20b, which are co-expressed with vascular endothelial growth factor (VEGF)-A and HIF-1 $\alpha$, also play important roles in breast cancer metastasis (Li et al., 2012) (Table 1).

IncRNAs are novel molecules that participate in a broad range of biological processes and complex diseases, especially in cancer progression. For example, the oncofetal H19 lncRNA is concomitantly induced by both transforming growth factor beta (TGF- $\beta$ ) and hypoxia in a mouse breast cancer model, and regulates E-cadherin expression and stimulates tumor metastasis through a positive feedback loop between Slug and H19/miR-675 (Matouk et al., 2014). Several other IncRNAs, such as linc-RoR (regulator of reprogramming) and UCA1 (urothelial cancer associated 1), have been proved to be regulated by hypoxia/HIF-1 $\alpha$, but their detailed mechanistic functions remain elusive (Takahashi et al., 2013; Hou et al., 2014; Huang et al., 2014; Xue et al., 2014) (Table 1).

Table 1 Examples of the hypoxia/HIF-1 $\alpha$ regulated ncRNAs in cancer metastasis

\begin{tabular}{|c|c|c|c|c|c|}
\hline ncRNA & $\begin{array}{c}\text { Type } \\
\text { (genomic location) }\end{array}$ & $\begin{array}{l}\text { Regulation } \\
\text { by hypoxia }\end{array}$ & $\begin{array}{l}\text { Effect on } \\
\text { metastasis }\end{array}$ & $\begin{array}{l}\text { Target gene or } \\
\text { effector }\end{array}$ & Reference \\
\hline $\mathrm{miR}-10 \mathrm{~b}$ & MicroRNA (chr 2) & $\uparrow$ & $\uparrow$ & HOXD10 & $\begin{array}{l}\text { Ma et al., 2007; Haque et } \\
\text { al., } 2011\end{array}$ \\
\hline miR-20a & MicroRNA (chr 13) & $\downarrow$ & $\downarrow$ & VEGF-A & Li et al., 2012 \\
\hline miR-20b & MicroRNA (chr X) & $\downarrow$ & $\downarrow$ & VEGF-A & $\begin{array}{l}\text { Cascio et al., 2010; Li et } \\
\quad \text { al., } 2012\end{array}$ \\
\hline $\operatorname{miR}-210$ & MicroRNA (chr 11) & $\uparrow$ & $\uparrow$ & $\begin{array}{l}\text { BRCA1, FANCD, } \\
\text { FANCF, PARP1, } \\
\text { E-cadherin, Rb1 }\end{array}$ & $\begin{array}{l}\text { Camps et al., 2008; Rothé } \\
\text { et al., 2011; Volinia et } \\
\text { al., } 2012\end{array}$ \\
\hline miR-24 & MicroRNA (chr X) & $\uparrow$ & $\uparrow$ & $\begin{array}{l}\text { PTPN9, PTPRF, } \\
\text { Sprouty2 (SPRY2) }\end{array}$ & $\begin{array}{r}\text { Kulshreshtha et al., 2007; } \\
\text { Du et al., 2013; Li et al., } \\
\text { 2013; Camps et al., } 2014\end{array}$ \\
\hline $\operatorname{miR}-27 a$ & MicroRNA (chr 19) & $\uparrow$ & $\uparrow$ & Sprouty2 (SPRY2) & $\begin{array}{l}\text { Kulshreshtha et al., 2007; } \\
\text { Camps } \text { et al., 2014; Li et } \\
\text { al., } 2013\end{array}$ \\
\hline $\operatorname{miR}-372 / 373$ & MicroRNA (chr 19) & $\uparrow$ & $\uparrow$ & $\begin{array}{l}\text { RECK, NF- } \kappa \mathrm{B} \text {, and } \\
\text { TGF- } \beta \text { pathways }\end{array}$ & $\begin{array}{r}\text { Loayza-Puch et al., 2010; } \\
\text { Keklikoglou et al., } 2012\end{array}$ \\
\hline $\operatorname{miR}-495$ & MicroRNA (chr 14) & $\uparrow$ & $\uparrow$ & E-cadherin, REDD1 & $\begin{array}{l}\text { Hwang-Verslues et al., } \\
2011\end{array}$ \\
\hline $\operatorname{miR}-675$ & MicroRNA (chr 11) & $\uparrow$ & $\uparrow$ & $\begin{array}{l}\text { RECK, NF- } \kappa B \text {, and } \\
\text { TGF- } \beta \text { pathways }\end{array}$ & $\begin{array}{r}\text { Loayza-Puch et al., 2010; } \\
\text { Keklikoglou et al., } 2012\end{array}$ \\
\hline $\begin{array}{l}\text { Oncofetal } \\
\text { H19 RNA }\end{array}$ & $\operatorname{lncRNA}(\mathrm{chr} 11)$ & $\uparrow$ & $\uparrow$ & $\begin{array}{l}\text { Slug, E-cadherin, } \\
\text { angiogenin, FGF18 }\end{array}$ & $\begin{array}{l}\text { Matouk et al., 2007; 2010; } \\
2014\end{array}$ \\
\hline linc-RoR & $\operatorname{lncRNA}(\mathrm{chr} 18)$ & $\uparrow$ & $\uparrow$ & mi-205, ZEB2 & $\begin{array}{l}\text { Takahashi et al., 2013; } \\
\text { Hou et al., } 2014\end{array}$ \\
\hline UCA1 & $\operatorname{lncRNA}(\mathrm{chr} 19)$ & $\uparrow$ & $\uparrow$ & p27 (Kip1) & $\begin{array}{l}\text { Huang et al., 2014; Xue et } \\
\text { al., } 2014\end{array}$ \\
\hline
\end{tabular}

chr: chromosome; lncRNA: long non-coding RNA; HOXD10: homeobox D10; VEGF-A: vascular endothelial growth factor A; BRCA1: breast cancer 1; FANCD: Fanconi anemia, complementation group D; FANCF: Fanconi anemia, complementation group F; PARP1: poly(ADP-ribose) polymerase 1; RB1: retinoblastoma 1; PTPN9: protein tyrosine phosphatase, non-receptor type 9; PTPRF: protein tyrosine phosphatase, receptor type F; RECK: reversion-inducing-cysteine-rich protein with Kazal motifs; NF-kB: nuclear factor of kappa light polypeptide gene enhancer in B cells; TGF- $\beta$ : transforming growth factor $\beta$; REDD1: DNA-damage-inducible transcript 4; FGF18: fibroblast growth factor 18; ZEB2: zinc finger E-box binding homeobox 2; p27: p27 protein; UCA1: urothelial cancer associated 1 


\section{HIF-1 as a therapeutic target}

Solid tumors, including breast cancers, contain a hypoxic microenvironment due to poor vascularization in the rapidly growing tumor tissues and fast proliferation of cancer cells. HIF-1 plays a pivotal role in the adaptation of cancer cells to hypoxia by activating transcription of target genes that regulate angiogenesis, cell proliferation and survival, glucose metabolism, $\mathrm{pH}$ regulation, migration, invasion, and metastasis (Kim et al., 2006; Fukuda et al., 2007; Zhang et al., 2007; Semenza, 2011; 2012). Increased HIF-1 expression shows strong correlations with poor prognostic outcomes and low survival rates of patients with breast cancers (Rose et al., 2003). Therefore, targeting the HIF pathway provides an attractive strategy to treat hypoxic tumors. The HIF-1 pathway is activated in the basal molecular subtype of breast cancer (Cancer Genome Atlas Network, 2012), suggesting that HIF-1 inhibitors may be particularly effective in the treatment of triple negative breast cancers.

The current HIF-1 inhibitors are classified by their mechanism of action and include those that affect HIF-1 $\alpha$ protein levels, HIF-1 dimerization, HIF-1 DNA binding, or HIF-1 transactivation of target genes (Table 2). Inhibitors that decrease HIF-1 $\alpha$ protein levels can be further divided into two groups, inhibitors of HIF- $1 \alpha$ translation and inducers of HIF- $1 \alpha$ proteasomal degradation. HIF-1 inhibitors, such as digoxin and acriflavine, showed convincing potential therapeutic effects by decreasing primary tumor growth, vascularization, invasion and metastasis in animal models of breast cancer (Lee et al., 2008; Zhang et al., 2008; 2012; Wong et al., 2011; 2012; Schito et al., 2012).

The combination of HIF inhibitors with existing treatments may prove to be useful clinically. Currently, for breast cancer therapy, the selective estrogen receptor (ER) modulator tamoxifen is widely used. Combination chemotherapy using trastuzumab targeting human epidermal growth factor receptor 2 (HER2) and bevacizumab targeting VEGF is another widely used therapeutic strategy. However, triple negative breast cancers respond poorly to currently available therapies. Since the HIF-1 pathway is highly activated in triple negative breast cancers, HIF-1 inhibitors could be effective in treatment of such cancers. Clinical trials are warranted to determine if they may increase the survival of breast cancer patients alone or in combination with current therapeutic regimens.

\section{Concluding remarks and future directions}

HIF-1, as a master regulator of cell response to hypoxic stress, plays important roles in breast cancer metastasis. As summarized in Fig. 2, HIF-1 is involved in almost every key step of the metastatic process, such as EMT, invasion, intravasation, extravasation, and metastatic niche formation, as discussed in detail in this review.

Table 2 Inhibitors of HIF-1 pathway

\begin{tabular}{|c|c|}
\hline Mechanism of action & Inhibitor \\
\hline Inhibition of HIF-1 $\alpha$ mRNA & Aminoflavone, GL331 \\
\hline $\begin{array}{l}\text { Inhibition of HIF-1 } \alpha \text { protein } \\
\text { synthesis }\end{array}$ & $\begin{array}{l}\text { Topoisomerase inhibitors (such as rapamycin, temsirolimus, and everolimus); } \\
\text { cardiac glycosides (such as digoxin and digtoxin), microtubule targeting } \\
\text { agents (such as 2-methoxyestradiol, epothilone B, and taxotere), topoiso- } \\
\text { merase inhibitors (such as camptothecin, topotecan, and NSC 644221), oli- } \\
\text { gonucleotides, AF, PX-478 }\end{array}$ \\
\hline $\begin{array}{l}\text { Inhibition of HIF-1 } \alpha \text { protein } \\
\text { stabilization }\end{array}$ & $\begin{array}{l}\text { HSP90 inhibitors (such as 17-AAG, 17-DMAG, and apigenin), HDAC inhibi- } \\
\text { tors (such as FK228 and LAQ824), antioxidants (such as ascorbic acid), ol- } \\
\text { igonucleotides, selenium compound (such as berberine and MSC), PX-12, } \\
\text { YC-1 }\end{array}$ \\
\hline $\begin{array}{l}\text { Inhibition of HIF-1 } \alpha: H I F-1 \beta \\
\text { dimerization }\end{array}$ & Acriflavine \\
\hline Inhibitions of HIF-1:DNA binding & Anthracyclines, echinomycin \\
\hline Inhibition of HIF-1 transactivity & Bortezomib \\
\hline
\end{tabular}




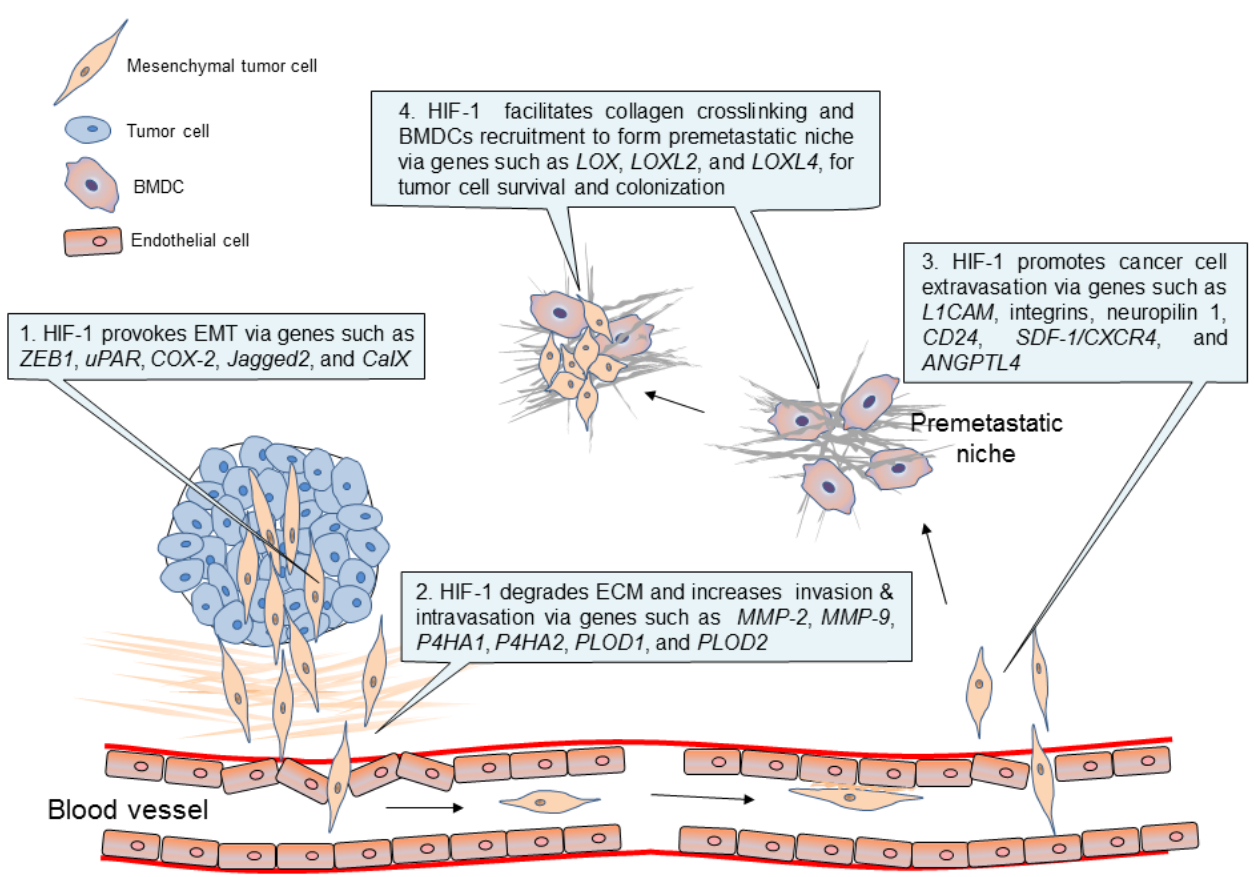

BMDC: bone marrow-derived cell; LOX: lysyl oxidase; EMT: epithelial-mesenchymal transition; ZEB1: zinc finger E-box-binding homeobox 1; uPAR: urokinasetype plasminogen activator receptor; CalX: carbonic anhydrase IX; L1CAM: L1 cell adhesion molecule; SDF-1/CXCR4: stromal cell-derived factor-1/CXC chemokine receptor 4; ANGPTL4: angiopoietin-like 4; MMP: matrix metallo-proteinase; P4HA: prolyl 4-hydroxylase $\alpha$-subunit; PLOD: procollagen-lysine 2-oxoglutarate 5-dioxygenase

Fig. 2 Cancer metastasis regulated by HIF-1

While most current studies have focused on HIF-1-regulated proteins, such as transcription factors, repressors and cytokines, recently, there has been growing appreciation of the role of ncRNAs, especially miRNAs and lncRNAs connected with HIF-1 controlled breast cancer metastasis. More comprehensive studies in this regard will shed light on the mechanisms underlying the regulation of hypoxia in breast cancer metastasis. A new concept has also been proposed that involves cancer stem cells in the connections between hypoxia and cancer metastasis (Hill et al., 2009). The metastasis-promoting effects of HIF-1 help to maintain an expanding/ renewing population of cancer stem cells ready to be distributed much like seeds or pollen blowing in the wind (Philip et al., 2013). A few studies have supported this point of view by demonstrating that hypoxia/HIF-1 induces cancer stem-like cells by Jagged2 or mediates paracrine signaling between breast cancer cells and mesenchymal stem cells to promote metastasis (Xing et al., 2011; Chaturvedi et al., 2013). Further studies along these lines will be potentially valuable for dissecting the mechanisms of breast cancer metastasis.
Thus, while intensive mechanistic studies are under way, targeting HIF-1 has emerged as a new therapeutic approach for treating breast cancer patients. Novel strategies targeting HIF-1 are likely to be useful in combination with current therapeutic regimens. Future work is warranted to identify more selective HIF-1 inhibitors, to study their mechanism of action, and to incorporate them in clinical trials.

\section{Compliance with ethics guidelines}

Zhao-ji LIU, Gregg L. SEMENZA, and Hua-feng ZHANG declare that they have no conflict of interest.

This article does not contain any studies with human or animal subjects performed by any of the authors.

\section{References}

Bao, B., Azmi, A.S., Ali, S., et al., 2012. The biological kinship of hypoxia with CSC and EMT and their relationship with deregulated expression of miRNAs and tumor aggressiveness. BBA Rev. Cancer, 1826(2): 272-296. [doi:10.1016/j.bbcan.2012.04.008]

Bocca, C., Ievolella, M., Autelli, R., et al., 2014. Expression of Cox-2 in human breast cancer cells as a critical determinant of epithelial-to-mesenchymal transition and invasiveness. Exp. Opin. Therap. Targets, 18(2):121-135. [doi:10.1517/14728222.2014.860447] 
Bos, R., van der Groep, P., Greijer, A.E., et al., 2003. Levels of hypoxia-inducible factor- $1 \alpha$ independently predict prognosis in patients with lymph node negative breast carcinoma. Cancer, 97(6):1573-1581. [doi:10.1002/cncr. 11246]

Brizel, D.M., Scully, S.P., Harrelson, J.M., et al., 1996. Tumor oxygenation predicts for the likelihood of distant metastases in human soft tissue sarcoma. Cancer Res., 56(5): 941-943.

Camps, C., Buffa, F.M., Colella, S., et al., 2008. hsa-miR-210 is induced by hypoxia and is an independent prognostic factor in breast cancer. Clin. Cancer Res., 14(5):13401348. [doi:10.1158/1078-0432.CCR-07-1755]

Camps, C., Saini, H.K., Mole, D.R., et al., 2014. Integrated analysis of microRNA and mRNA expression and association with HIF binding reveals the complexity of microRNA expression regulation under hypoxia. Mol. Cancer, 13:28. [doi:10.1186/1476-4598-13-28]

Cancer Genome Atlas Network, 2012. Comprehensive molecular portraits of human breast tumours. Nature, 490(7418):61-70. [doi:10.1038/nature11412]

Cascio, S., D'Andrea, A., Ferla, R., et al., 2010. miR-20b modulates VEGF expression by targeting HIF-1 $\alpha$ and STAT3 in MCF-7 breast cancer cells. J. Cell. Physiol., 224(1):242-249. [doi:10.1002/jcp.22126]

Chaffer, C.L., Weinberg, R.A., 2011. A perspective on cancer cell metastasis. Science, 331(6024):1559-1564. [doi:10. 1126/science.1203543]

Chaturvedi, P., Gilkes, D.M., Wong, C.C., et al., 2013. Hypoxiainducible factor-dependent breast cancer-mesenchymal stem cell bidirectional signaling promotes metastasis. $J$. Clin. Invest., 123(1):189-205. [doi:10.1172/JCI64993]

Conklin, M.W., Eickhoff, J.C., Riching, K.M., et al., 2011. Aligned collagen is a prognostic signature for survival in human breast carcinoma. Am. J. Pathol., 178(3): 1221-1232. [doi:10.1016/j.ajpath.2010.11.076]

Creighton, C.J., Chang, J.C., Rosen, J.M., 2010. Epithelialmesenchymal transition (EMT) in tumor-initiating cells and its clinical implications in breast cancer. J. Mammary Gland Biol. Neopl., 15(2):253-260. [doi:10.1007/ s10911-010-9173-1]

Davis, F.M., Azimi, I., Faville, R.A., et al., 2014. Induction of epithelial-mesenchymal transition (EMT) in breast cancer cells is calcium signal dependent. Oncogene, 33(18): 2307-2316. [doi:10.1038/onc.2013.187]

Du, W.W., Fang, L., Li, M., et al., 2013. MicroRNA miR-24 enhances tumor invasion and metastasis by targeting PTPN9 and PTPRF to promote EGF signaling. J. Cell Sci., 126(6):1440-1453. [doi:10.1242/jcs.118299]

Duffy, M.J., Maguire, T.M., Hill, A., et al., 2000. Metalloproteinases: role in breast carcinogenesis, invasion and metastasis. Breast Cancer Res., 2(4):252-257. [doi:10. 1186/bcr65]

Erler, J.T., Bennewith, K.L., Nicolau, M., et al., 2006. Lysyl oxidase is essential for hypoxia-induced metastasis. Nature, 440(7088):1222-1226. [doi:10.1038/nature04695]

Erler, J.T., Bennewith, K.L., Cox, T.R., et al., 2009. Hypoxiainduced lysyl oxidase is a critical mediator of bone marrow cell recruitment to form the premetastatic niche. Cancer Cell, 15(1):35-44. [doi:10.1016/j.ccr.2008.11.012]

Feldser, D., Agani, F., Iyer, N.V., et al., 1999. Reciprocal positive regulation of hypoxia-inducible factor $1 \alpha$ and insulin-like growth factor 2. Cancer Res., 59(16): 3915-3918.

Fidler, I.J., 1970. Metastasis: quantitative analysis of distribution and fate of tumor emboli labeled with ${ }^{125}$ I-5-iodo-2'deoxyuridine. J. Natl. Cancer Inst., 45(4):773-782.

Fukuda, N., Nakayama, M., Jian, T., et al., 2003. Leukocyte angiotensin II levels in patients with essential hypertension: relation to insulin resistance. Am. J. Hypertens., 16(2):129-134. [doi:10.1016/S0895-7061(02)03145-X]

Fukuda, R., Hirota, K., Fan, F., et al., 2002. Insulin-like growth factor 1 induces hypoxia-inducible factor 1-mediated vascular endothelial growth factor expression, which is dependent on MAP kinase and phosphatidylinositol 3-kinase signaling in colon cancer cells. J. Biol. Chem., 277(41):38205-38211. [doi:10.1074/jbc.M203781200]

Fukuda, R., Zhang, H.F., Kim, J.W., et al., 2007. HIF-1 regulates cytochrome oxidase subunits to optimize efficiency of respiration in hypoxic cells. Cell, 129(1):111-122. [doi:10.1016/j.cell.2007.01.047]

Gao, P., Zhang, H.F., Dinavahi, R., et al., 2007. HIF-dependent antitumorigenic effect of antioxidants in vivo. Cancer Cell, 12(3):230-238. [doi:10.1016/j.ccr.2007.08.004]

Generali, D., Berruti, A., Brizzi, M.P., et al., 2006. Hypoxiainducible factor- $1 \alpha$-expression predicts a poor response to primary chemoendocrine therapy and disease-free survival in primary human breast cancer. Clin. Cancer Res., 12(15):4562-4568. [doi:10.1158/1078-0432.CCR05-2690]

Gilkes, D.M., Bajpai, S., Chaturvedi, P., et al., 2013a. Hypoxia-inducible factor 1 (HIF-1) promotes extracellular matrix remodeling under hypoxic conditions by inducing P4HA1, P4HA2, and PLOD2 expression in fibroblasts. J. Biol. Chem., 288(15):10819-10829. [doi:10. 1074/jbc.M1 12.442939]

Gilkes, D.M., Bajpai, S., Wong, C.C., et al., 2013b. Procollagen lysyl hydroxylase 2 is essential for hypoxia-induced breast cancer metastasis. Mol. Cancer Res., 11(5): 456-466. [doi:10.1158/1541-7786.MCR-12-0629]

Gilkes, D.M., Chaturvedi, P., Bajpai, S., et al., 2013c. Collagen prolyl hydroxylases are essential for breast cancer metastasis. Cancer Res., 73(11):3285-3296. [doi:10. 1158/0008-5472.CAN-12-3963]

Grimshaw, M.J., 2007. Endothelins and hypoxia-inducible factor in cancer. Endocr. Rel. Cancer, 14(2):233-244. [doi:10.1677/ERC-07-0057]

Gruber, G., Greiner, R.H., Hlushchuk, R., et al., 2004. Hypoxia-inducible factor $1 \alpha$ in high-risk breast cancer: an independent prognostic parameter? Breast Cancer Res., 6(3):R191-R198. [doi:10.1186/bcr775]

Haque, I., Banerjee, S., Mehta, S., et al., 2011. Cysteine-rich 61-connective tissue growth factor-nephroblastomaoverexpressed 5 (CCN5)/Wnt-1-induced signaling protein-2 (WISP-2) regulates microRNA-10b via hypoxia-inducible factor- $1 \alpha$-TWIST signaling networks 
in human breast cancer cells. J. Biol. Chem., 286(50): 43475-43485. [doi:10.1074/jbc.M111.284158]

Hill, R.P., Marie-Egyptienne, D.T., Hedley, D.W., 2009. Cancer stem cells, hypoxia and metastasis. Semin. Radiat. Oncol., 19(2):106-111. [doi:10.1016/j.semradonc.2008. 12.002]

Hohenberger, P., Felgner, C., Haensch, W., et al., 1998. Tumor oxygenation correlates with molecular growth determinants in breast cancer. Breast Cancer Res. Treat., 48(2): 97-106. [doi:10.1023/A:1005921513083]

Horrée, N., van Diest, P.J., Daisy, M.D.S.G., et al., 2007. The invasive front in endometrial carcinoma: higher proliferation and associated derailment of cell cycle regulators. Human Pathol., 38(8):1232-1238. [doi:10.1016/j. humpath.2007.01.008]

Hou, P., Zhao, Y., Li, Z., et al., 2014. lincRNA-RoR induces epithelial-to-mesenchymal transition and contributes to breast cancer tumorigenesis and metastasis. Cell Death Dis., 5(6):e1287. [doi:10.1038/cddis.2014.249]

Hu, M., Polyak, K., 2008. Microenvironmental regulation of cancer development. Curr. Opin. Genet. Dev., 18(1): 27-34. [doi:10.1016/j.gde.2007.12.006]

Huang, J., Zhou, N., Watabe, K., et al., 2014. Long non-coding RNA UCA1 promotes breast tumor growth by suppression of p27 (Kip1). Cell Death Dis., 5(1):e1008. [doi:10. 1038/cddis.2013.541]

Huang, R.L., Teo, Z.Q., Chong, H.C., et al., 2011. ANGPTL4 modulates vascular junction integrity by integrin signaling and disruption of intercellular VE-cadherin and claudin-5 clusters. Blood, 118(14):3990-4002. [doi:10. 1182/blood-2011-01-328716]

Hugo, H.J., Pereira, L., Suryadinata, R., et al., 2013. Direct repression of MYB by ZEB1 suppresses proliferation and epithelial gene expression during epithelial-tomesenchymal transition of breast cancer cells. Breast Cancer Res., 15(6):R113. [doi:10.1186/bcr3580]

Hwang-Verslues, W.W., Chang, P.H., Wei, P.C., et al., 2011. miR-495 is upregulated by E12/E47 in breast cancer stem cells, and promotes oncogenesis and hypoxia resistance via downregulation of E-cadherin and REDD1. Oncogene, 30(21):2463-2474. [doi:10.1038/onc.2010.618]

Incorvaia, L., Badalamenti, G., Rini, G., et al., 2007. MMP-2, MMP-9 and activin A blood levels in patients with breast cancer or prostate cancer metastatic to the bone. Anticancer Res., 27(3B):1519-1525.

Jemal, A., Bray, F., Center, M.M., et al., 2011. Global cancer statistics. CA Cancer J. Clin., 61(2):69-90. [doi:10.3322/ caac.20107]

Jin, F.Y., Brockmeier, U., Otterbach, F., et al., 2012. New insight into the SDF-1/CXCR4 axis in a breast carcinoma model: hypoxia-induced endothelial SDF-1 and tumor cell CXCR4 are required for tumor cell intravasation. $\mathrm{Mol}$. Cancer Res., 10(8):1021-1031. [doi:10.1158/1541-7786. MCR-11-0498]

Jo, M., Lester, R.D., Montel, V., et al., 2009. Reversibility of epithelial-mesenchymal transition (EMT) induced in breast cancer cells by activation of urokinase receptordependent cell signaling. J. Biol. Chem., 284(34):
22825-22833. [doi:10.1074/jbc.M109.023960]

Kalluri, R., Weinberg, R.A., 2009. The basics of epithelialmesenchymal transition. J. Clin. Invest., 119(6):14201428. [doi:10.1172/JCI39104]

Kaplan, H.G., Malmgren, J.A., Atwood, M., 2005. Tumor size, age and stage in patient detected breast cancer. J. Clin. Oncol., 23(16):716.

Kasuno, K., Takabuchi, S., Fukuda, K., et al., 2004. Nitric oxide induces hypoxia-inducible factor 1 activation that is dependent on MAPK and phosphatidylinositol 3-kinase signaling. J. Biol. Chem., 279(4):2550-2558. [doi:10. 1074/jbc.M308197200]

Keklikoglou, I., Koerner, C., Schmidt, C., et al., 2012. MicroRNA-520/373 family functions as a tumor suppressor in estrogen receptor negative breast cancer by targeting NF- $\mathrm{kB}$ and TGF- $\beta$ signaling pathways. Oncogene, 31(37): 4150-4163. [doi:10.1038/onc.2011.571]

Kim, J.W., Tchernyshyov, I., Semenza, G.L., et al., 2006. HIF-1-mediated expression of pyruvate dehydrogenase kinase: a metabolic switch required for cellular adaptation to hypoxia. Cell Metab., 3(3):177-185. [doi:10.1016/j. cmet.2006.02.002]

Krieg, M., Haas, R., Brauch, H., et al., 2000. Up-regulation of hypoxia-inducible factors HIF- $1 \alpha$ and HIF- $2 \alpha$ under normoxic conditions in renal carcinoma cells by von Hippel-Lindau tumor suppressor gene loss of function. Oncogene, 19(48):5435-5443. [doi:10.1038/sj.onc.1203 938]

Krishnamachary, B., Zagzag, D., Nagasawa, H., et al., 2006. Hypoxia-inducible factor-1-dependent repression of E-cadherin in von Hippel-Lindau tumor suppressor-null renal cell carcinoma mediated by TCF3, ZFHX1A, and ZFHX1B. Cancer Res., 66(5):2725-2731. [doi:10.1158/ 0008-5472.CAN-05-3719]

Kulshreshtha, R., Ferracin, M., Wojcik, S.E., et al., 2007. A microRNA signature of hypoxia. Mol. Cell. Biol., 27(5): 1859-1867. [doi:10.1128/MCB.01395-06]

Lando, D., Peet, D.J., Whelan, D.A., et al., 2002. Asparagine hydroxylation of the HIF transactivation domain: a hypoxic switch. Science, 295(5556):858-861. [doi:10. 1126/science.1068592]

Laughner, E., Taghavi, P., Chiles, K., et al., 2001. Her2 (neu) signaling increases the rate of hypoxia-inducible factor 1 alpha (HIF-1 $\alpha$ ) synthesis: novel mechanism for HIF-1mediated vascular endothelial growth factor expression. Mol. Cell. Biol., 21(12):3995-4004. [doi:10.1128/MCB. 21.12.3995-4004.2001]

Lech, R., Przemyslaw, O., 2011. Epidemiological models for breast cancer risk estimation. Ginekol. Pol., 82(6): 451-454.

Lee, H.S., Seo, E.Y., Kang, N.E., et al., 2008. [6]-Gingerol inhibits metastasis of MDA-MB-231 human breast cancer cells. J. Nutr. Biochem., 19(5):313-319. [doi:10.1016/j. jnutbio.2007.05.008]

Li, J.Y., Zhang, Y., Zhang, W.H., et al., 2012. Differential distribution of miR-20a and miR-20b may underly metastatic heterogeneity of breast cancers. Asian Pac. J. Cancer Prev., 13(5):1901-1906. [doi:10.7314/APJCP. 
2012.13.5.1901]

Li, X., Liu, X., Xu, W., et al., 2013. c-MYC-regulated $m i R-23 a / 24-2 / 27 a$ cluster promotes mammary carcinoma cell invasion and hepatic metastasis by targeting Sprouty2 J. Biol. Chem., 288(25):18121-18133. [doi:10.1074/jbc. M113.478560]

Ling, H., Fabbri, M., Calin, G.A., 2013. MicroRNAs and other non-coding RNAs as targets for anticancer drug development. Nat. Rev. Drug Disc., 12(11):847-865. [doi:10. $1038 /$ nrd4140]

Liu, X.H., Kirschenbaum, A., Lu, M., et al., 2002. Prostaglandin $\mathrm{E}_{2}$ induces hypoxia-inducible factor- $1 \alpha$ stabilization and nuclear localization in a human prostate cancer cell line. J. Biol. Chem., 277(51):50081-50086. [doi:10. 1074/jbc.M201095200]

Loayza-Puch, F., Yoshida, Y., Matsuzaki, T., et al., 2010. Hypoxia and RAS-signaling pathways converge on, and cooperatively downregulate, the RECK tumor-suppressor protein through microRNAs. Oncogene, 29(18):26382648. [doi:10.1038/onc.2010.23]

Lock, F.E., Mcdonald, P.C., Lou, Y., et al., 2013. Targeting carbonic anhydrase IX depletes breast cancer stem cells within the hypoxic niche. Oncogene, 32(44):5210-5219. [doi:10.1038/onc.2012.550]

Lundgren, K., Holm, C., Landberg, G., 2007. Hypoxia and breast cancer: prognostic and therapeutic implications. Cell. Mol. Life Sci., 64(24):3233-3247. [doi:10.1007/ s00018-007-7390-6]

Ma, L., Teruya-Feldstein, J., Weinberg, R.A., 2007. Tumour invasion and metastasis initiated by microRNA-10b in breast cancer. Nature, 449(7163):682-688. [doi:10.1038/ nature06174]

Ma, L., Reinhardt, F., Pan, E., et al., 2010. Therapeutic silencing of miR-10b inhibits metastasis in a mouse mammary tumor model. Nat. Biotechnol., 28(4):341-347. [doi:10.1038/nbt.1618]

Maglione, E., Ferreira, L.S., Cattapan, G., 2006. Asymptotic properties of bound states in coupled quantum wave guides. J. Phys. A Math. General, 39(5):1207-1228. [doi:10.1088/0305-4470/39/5/013]

Mahon, P.C., Hirota, K., Semenza, G.L., 2001. FIH-1: a novel protein that interacts with HIF- $1 \alpha$ and VHL to mediate repression of HIF-1 transcriptional activity. Genes Devel., 15(20):2675-2686. [doi:10.1101/gad.924501]

Matouk, I.J., Degroot, N., Mezan, S., et al., 2007. The H19 non-coding RNA is essential for human tumor growth. PLoS ONE, 2(9):e845. [doi:10.1371/journal.pone.0000 845]

Matouk, I.J., Mezan, S., Mizrahi, A., et al., 2010. The oncofetal H19 RNA connection: hypoxia, p53 and cancer. BBA Mol. Cell Res., 1803(4):443-451. [doi:10.1016/j. bbamcr.2010.01.010]

Matouk, I.J., Raveh, E., Abu-Lail, R., et al., 2014. Oncofetal H19 RNA promotes tumor metastasis. BBA Mol. Cell Res., 1843(7):1414-1426. [doi:10.1016/j.bbamcr.2014.03.023]

May, C.D., Sphyris, N., Evans, K.W., et al., 2011. Epithelialmesenchymal transition and cancer stem cells: a dangerously dynamic duo in breast cancer progression.
Breast Cancer Res., 13(1):202. [doi:10.1186/bcr2789]

Mees, G., Dierckx, R., Vangestel, C., et al., 2009. Molecular imaging of hypoxia with radiolabelled agents. Eur. J. Nucl. Med. Mol. Imag., 36(10):1674-1686. [doi:10.1007/ s00259-009-1195-9]

Moreno-Bueno, G., Portillo, F., Cano, A., 2008. Transcriptional regulation of cell polarity in EMT and cancer. Oncogene, 27(55):6958-6969. [doi:10.1038/onc.2008.346]

Munoz-Najar, U.M., Neurath, K.M., Vumbaca, F., et al., 2006. Hypoxia stimulates breast carcinoma cell invasion through MT1-MMP and MMP-2 activation. Oncogene, 25(16):2379-2392. [doi:10.1038/sj.onc.1209273]

Padua, D., Zhang, X.H.F., Wang, Q.Q., et al., 2008. TGF- $\beta$ primes breast tumors for lung metastasis seeding through angiopoietin-like 4. Cell, 133(1):66-77. [doi:10.1016/j. cell.2008.01.046]

Philip, B., Ito, K., Moreno-Sanchez, R., et al., 2013. HIF expression and the role of hypoxic microenvironments within primary tumours as protective sites driving cancer stem cell renewal and metastatic progression. Carcinogenesis, 34(8):1699-1707. [doi:10.1093/carcin/bgt209]

Pritchard, S.C., Nicolson, M.C., Lloret, C., et al., 2001. Expression of matrix metalloproteinases 1, 2, 9 and their tissue inhibitors in stage II non-small cell lung cancer: implications for MMP inhibition therapy. Oncol. Rep., 8(2):421-424.

Provenzano, P.P., Eliceiri, K.W., Campbell, J.M., et al., 2006. Collagen reorganization at the tumor-stromal interface facilitates local invasion. BMC Med., 4(1):38. [doi:10. 1186/1741-7015-4-38]

Quintero, M., Brennan, P.A., Thomas, G.J., et al., 2006. Nitric oxide is a factor in the stabilization of hypoxia-inducible factor- $1 \alpha$ in cancer: role of free radical formation. Cancer Res., 66(2):770-774. [doi:10.1158/0008-5472.CAN-050333]

Ravi, D., Ramadas, K., Mathew, B.S., et al., 2001. Apoptosis, angiogenesis and proliferation: trifunctional measure of tumour response to radiotherapy for oral cancer. Oral Oncol., 37(2):164-171. [doi:10.1016/S1368-8375(00) 00082-8]

Rose, C., Vtoraya, O., Pluzanska, A., et al., 2003. An open randomised trial of second-line endocrine therapy in advanced breast cancer. Comparison of the aromatase inhibitors letrozole and anastrozole. Eur. J. Cancer, 39(16): 2318-2327. [doi:10.1016/S0959-8049(03)00630-0]

Rothé, F., Ignatiadis, M., Chaboteaux, C., et al., 2011. Global microRNA expression profiling identifies miR-210 associated with tumor proliferation, invasion and poor clinical outcome in breast cancer. PLoS ONE, 6(6): e20980. [doi:10.1371/journal.pone.0020980]

Sceneay, J., Chow, M.T., Chen, A., et al., 2012. Primary tumor hypoxia recruits $\mathrm{CD} 11 \mathrm{~b}^{+} / \mathrm{Ly} 6 \mathrm{C}^{\text {med }} / \mathrm{Ly}_{6 \mathrm{G}}{ }^{+}$immune suppressor cells and compromises NK cell cytotoxicity in the premetastatic niche. Cancer Res., 72(16):3906-3911. [doi:10.1158/0008-5472.CAN-11-3873]

Schito, L., Rey, S., Tafani, M., et al., 2012. Hypoxia-inducible factor 1-dependent expression of platelet-derived growth factor $b$ promotes lymphatic metastasis of hypoxic breast 
cancer cells. PNAS, 109(40):E2707-E2716. [doi:10.1073/ pnas.1214019109]

Semenza, G.L., 2003. Targeting HIF-1 for cancer therapy. Nat. Rev. Cancer, 3(10):721-732. [doi:10.1038/nrc1187]

Semenza, G.L., 2011. Oxygen sensing, homeostasis, and disease reply. N. Engl. J. Med., 365(19):537-547. [doi:10. 1056/NEJMra1011165]

Semenza, G.L., 2012. Hypoxia-inducible factors: mediators of cancer progression and targets for cancer therapy. Trends Pharmacol. Sci., 33(4):207-214. [doi:10.1016/j.tips.2012. 01.005]

Singh, A., Settleman, J., 2010. EMT, cancer stem cells and drug resistance: an emerging axis of evil in the war on cancer. Oncogene, 29(34):4741-4751. [doi:10.1038/onc. 2010.215]

Takahashi, K., Yan, I.K., Haga, H., et al., 2013. The hypoxiainduced long non-coding RNA linc-RoR modulates tumor cell resistance to hypoxia by an extra-cellular vesicle mediated regulation of hypoxia-signaling pathways in hepatocellular cancer. Hepatology, 58:1067A.

Talks, K.L., Turley, H., Gatter, K.C., et al., 2000. The expression and distribution of the hypoxia-inducible factors HIF- $1 \alpha$ and HIF- $\alpha$ in normal human tissues, cancers, and tumor-associated macrophages. Am. J. Pathol., 157(2): 411-421. [doi:10.1016/S0002-9440(10)64554-3]

Thiery, J.P., 2002. Epithelial-mesenchymal transitions in tumour progression. Nat. Rev. Cancer, 2(6):442-454. [doi:10.1038/nrc822]

Valastyan, S., Weinberg, R.A., 2011. Tumor metastasis: molecular insights and evolving paradigms. Cell, 147(2): 275-292. [doi:10.1016/j.cell.2011.09.024]

Vaupel, P., Schlenger, K., Knoop, C., et al., 1991. Oxygenation of human tumors: evaluation of tissue oxygen distribution in breast cancers by computerized $\mathrm{O}_{2}$ tension measurements. Cancer Res., 51(12):3316-3322.

Vaupel, P., Mayer, A., Hockel, M., 2004. Tumor hypoxia and malignant progression. Meth. Enzymol., 381:335-354. [doi:10.1016/S0076-6879(04)81023-1]

Vaupel, P., Hockel, M., Mayer, A., 2007. Detection and characterization of tumor hypoxia using $\mathrm{pO}_{2}$ histography. Antioxid. Redox. Signal., 9(8):1221-1235. [doi:10.1089/ ars.2007.1628]

Volinia, S., Galasso, M., Sana, M.E., et al., 2012. Breast cancer signatures for invasiveness and prognosis defined by deep sequencing of microRNA. PNAS, 109(8): 3024-3029. [doi:10.1073/pnas.1200010109]

Wang, G.L., Jiang, B.H., Rue, E.A., et al., 1995. Hypoxiainducible factor-1 is a basic-helix-loop-helix-pas heterodimer regulated by cellular $\mathrm{O}_{2}$ tension. PNAS, 92(12): 5510-5514. [doi:10.1073/pnas.92.12.5510]

Weigelt, B., Peterse, J.L., van't Veer, L.J., 2005. Breast cancer metastasis: markers and models. Nat. Rev. Cancer, 5(8): 591-602. [doi:10.1038/nrc1670]

Wong, C.C.L., Gilkes, D.M., Zhang, H.F., et al., 2011. Hypoxia-inducible factor 1 is a master regulator of breast cancer metastatic niche formation. PNAS, 108(39): 16369-16374. [doi:10.1073/pnas.1113483108]

Wong, C.C.L., Zhang, H., Gilkes, D.M., et al., 2012. Inhibitors of hypoxia-inducible factor 1 block breast cancer metastatic niche formation and lung metastasis. J. Mol. Med., 90(7):803-815. [doi:10.1007/s00109-011-0855-y]

Xing, F., Okuda, H., Watabe, M., et al., 2011. Hypoxiainduced Jagged 2 promotes breast cancer metastasis and self-renewal of cancer stem-like cells. Oncogene, 30(39): 4075-4086. [doi:10.1038/onc.2011.122]

Xue, M., Li, X., Li, Z., et al., 2014. Urothelial carcinoma associated 1 is a hypoxia-inducible factor- $1 \alpha$-targeted long noncoding RNA that enhances hypoxic bladder cancer cell proliferation, migration, and invasion. Tumour Biol., 35(7):6901-6912. [doi:10.1007/s13277-014-1925-x]

Zhang, H., Gao, P., Fukuda, R., et al., 2007. HIF-1 inhibits mitochondrial biogenesis and cellular respiration in VHLdeficient renal cell carcinoma by repression of C-MYC activity. Cancer Cell, 11(5):407-420. [doi:10.1016/j.ccr. 2007.04.001]

Zhang, H., Qian, D.Z., Tan, Y.S., et al., 2008. Digoxin and other cardiac glycosides inhibit HIF-1 $\alpha$ synthesis and block tumor growth. PNAS, 105(50):19579-19586. [doi:10.1073/pnas.0809763105]

Zhang, H., Wong, C.C.L., Wei, H., et al., 2012. HIF-1dependent expression of angiopoietin-like 4 and L1CAM mediates vascular metastasis of hypoxic breast cancer cells to the lungs. Oncogene, 31(14):1757-1770. [doi:10. 1038/onc.2011.365]

Zhong, H., de Marzo, A.M., Laughner, E., et al., 1999. Overexpression of hypoxia-inducible factor $1 \alpha$ in common human cancers and their metastases. Cancer Res., 59(22): $5830-5835$.

Zhong, H., Chiles, K., Feldser, D., et al., 2000. Modulation of hypoxia-inducible factor $1 \alpha$ expression by the epidermal growth factor/phosphatidylinositol 3-kinase/PTEN/AKT/ FRAP pathway in human prostate cancer cells: implications for tumor angiogenesis and therapeutics. Cancer Res., 60(6):1541-1545.

Zundel, W., Schindler, C., Haas-Kogan, D., et al., 2000. Loss of PTEN facilitates HIF-1-mediated gene expression. Gene Devel., 14(4):391-396.

\section{中文概要}

\section{题 目: 低氧诱导因子与乳腺癌转移}

概 要: 肿瘤, 特别是实体瘤, 其内部微环境处于一种低 氧或缺氧的状态, 肿瘤的这种低氧微环境将诱导 活化低氧诱导因子 (HIF-1) 信号通路。HIF-1 信 号通路在乳腺癌的转移中发挥着重要的作用。乳 腺癌的转移涉及肿瘤细胞的浸润、进入血管、通 过血液循环迁移、到达远端毛细血管内壁、穿透 血管壁进入新的器官以及在新的部位形成转移 灶等步骤, 过程非常复杂。本文重点围绕 HIF-1 在转移各个步骤中的作用进行综述。

关键词: 乳腺癌; 低氧诱导因子; 肿瘤转移 